Terr. Atmos. Ocean. Sci., Vol. 18, No. 2, 129-141, June 2007

\title{
Investigating the TCDP Drill Site Using Deep and Shallow Reflection Seismics
}

\author{
Chien-Ying Wang ${ }^{1,}{ }^{*}$, Chien-Li Lee ${ }^{1}$, Ming-Chiun Wu ${ }^{1,3}$, and Mang-Long Ger ${ }^{2}$
}

(Manuscript received 13 January 2006, in final form 30 September 2006)

\begin{abstract}
The 1999 Chi-Chi earthquake $\left(M_{w}=7.6\right)$, Taiwan, reactivated the 105 km long, NS trending Chelungpu fault causing extraordinary surface ruptures. The distribution of the ruptures was quite heterogeneous with the largest displacement (up to $12 \mathrm{~m}$ ) occurring across the Tachia River, $50 \mathrm{~km}$ north of the epicenter. In this study, several different scaled seismic lines are constrained and used to predict the major regional fault geometry. The 3D northern lateral ramp of the Chelungpu fault is clearly found, which provides a structural framework to explain the en echelon surface ruptures around the Tachia River.

These data were also applied to identify the strata connected with the site of a $2 \mathrm{~km}$ hole (the Taiwan Chelungpu-fault Drilling Project, TCDP). Adequate site conditions are predicted before drilling and rechecked after drilling. A 'TT-boundary' is proposed as a structural control of the faulting in the area, which shapes the strata to dip $30^{\circ}$ east and $20^{\circ}$ south at the drill site. A depth of $1100 \mathrm{~m}$ for the Chi-Chi earthquake fault zone was predicted and confirmed. This is a good example, combining different scaled seismic methods to study detailed underground structures, which has the drilling purpose.
\end{abstract}

(Key words: Chi-Chi earthquake, Chelungpu fault, Reflection seismics, TCDP)

\footnotetext{
${ }^{1}$ Department of Earth Sciences and Institute of Geophysics, National Central University, Chung-Li, Taiwan, ROC

2 Institute of Geography, National Taiwan Normal University, Taipei, Taiwan, ROC

${ }^{3}$ Chinese Petroleum Corporation, Taipei, Taiwan, ROC

* Corresponding author address: Prof. Chien-Ying Wang, Department of Earth Sciences and Institute of Geophysics, National Central University, Chung-Li, Taiwan, ROC; E-mail: wangcy@cc.ncu.edu.tw doi: 10.3319/TAO.2007.18.2.129(TCDP)
} 


\section{INTRODUCTION}

The Chelungpu fault is an active fault (identified prior to the earthquake) located along the border of the Western Foothills in central Taiwan (Fig. 1). This fault was reactivated during the Chi-Chi earthquake $\left(M_{w}=7.6\right) 21$ September 1999, which caused great damage throughout the island (Shin and Teng 2001). The Chelungpu fault is composed of two segments: a $90 \mathrm{~km}$ long NS oriented main part, and a $15 \mathrm{~km}$ long EW branch at the northern end. The main NS fault is considered to be a bedding-parallel thrust fault that slips along the Chinshui Shale, which is probably a 'decollement' in the thin-skinned thrust model (Suppe 1985; Wang et al. 2000). The EW branch at the northern end, on the other hand, is quite peculiar in that abnormally large displacements (9.8 m vertically and $12 \mathrm{~m}$ horizontally) occurred both on the surface and underground (Ma et al. 2001). This branch also experienced 'en echelon' ruptures about $1 \sim 2 \mathrm{~km}$ in width along the Tachia River, and then along the existing Tungshih anticline to its northern edge (Fig. 1b).

The damage caused by the Chelungpu fault was much more serious on the hanging wall (eastern) side due to its reverse faulting characteristics. From the earthquake record analysis, it is also found that the faulting at the northern part possessed low peak ground acceleration (PGA) but high peak ground displacement (PGD; Ma et al. 2001). It seems that the northern fault moved smoothly, but generated large displacements. These peculiar phenomena make a focus on the north-eastern portion of the fault, which may be worth intense examinations.

We have already conducted dense surveys using shallow reflection seismics in the northeastern region (Wang et al. 2004). Figure 1a depicts these shallow seismic lines. An approximate 3D picture of the area's structure could thus be developed. In general, the Chelungpu fault dips uniformly to the east by 20 - 40 degrees. This fault surface is also found to have an undulating shape with a gentle 10 degree dip to the south (Wang 2002; Wang et al. 2004). The up-and-down variation of the fault surface in the SN direction may affect the topographic and near-surface geologic configurations. The agreement of the surface and underground structures provides evidence that the Chelungpu fault is young, possibly still shaping the landforms.

There is another fault situated below the Chelungpu fault, called the Sanyi fault (Fig. 1b). This older fault is of an over-thrust type and is exposed to the north (Meng 1963). This Sanyi fault is quite significant in that it controls the southern boundary of the Maioli gas field (north of the Ta-An River). Both faults are 'decollement' type faults, but slipping at different depths within different layers (Hung and Wiltschko 1993). The interaction between these two faults in the 1999 earthquake is unclear.

After the 1999 earthquake, two shallow test wells were drilled on the northern and southern sides of the fault (Tanaka et al. 2002). The northern well, $450 \mathrm{~m}$ deep, shows four fracture zones, each about 20 - $30 \mathrm{~m}$ long. Of these, two (225 and $330 \mathrm{~m})$ are supposedly related to the 1999 earthquake. It is quite interesting that a high water content (up to $45 \mathrm{vol} . \%$ ) was found at the $225 \mathrm{~m}$ fracture zone. The southern well, $200 \mathrm{~m}$ deep, is simpler having only one $60-\mathrm{m}$ long fracture zone, directly above the 1999 faulting position. Many pseudotachylites were identified in the southern well, which may have been produced by the friction of rocks during many previous earthquake faultings. The totally different borehole conditions at both wells suggest the necessity of further research on both parts of the fault. 
Wang et al.

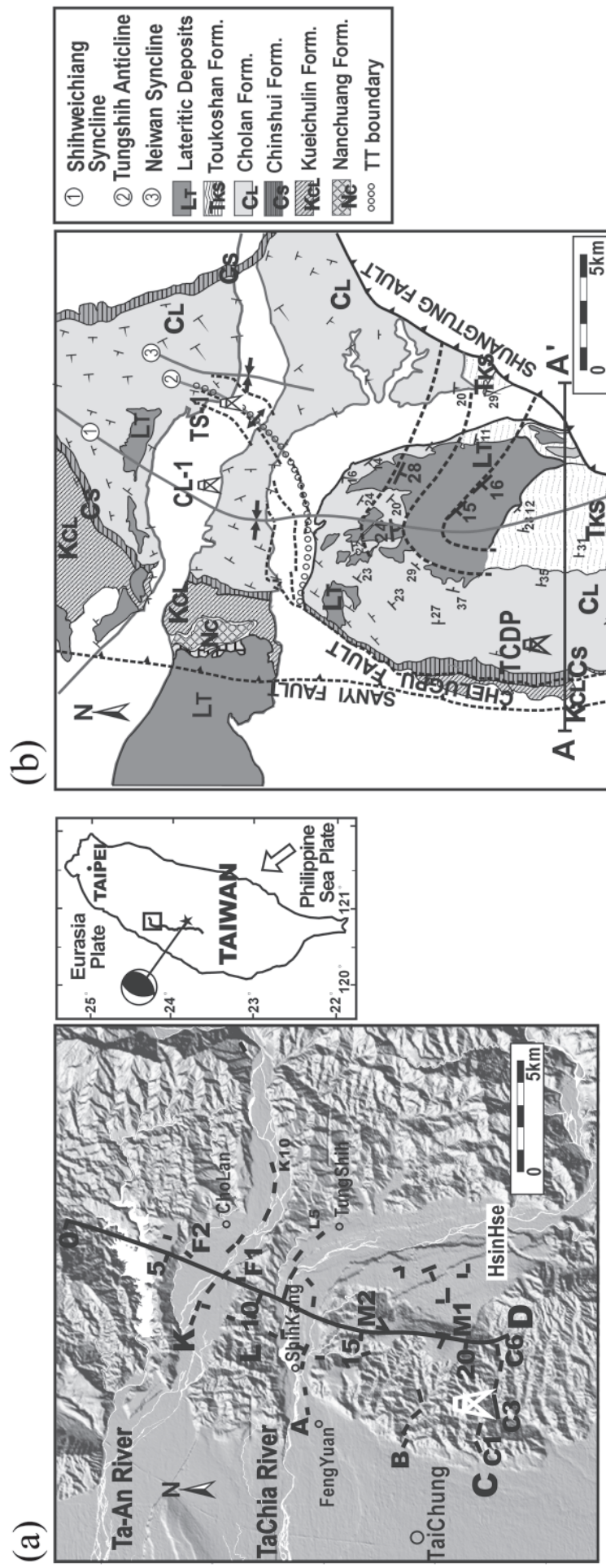

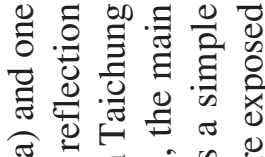

.

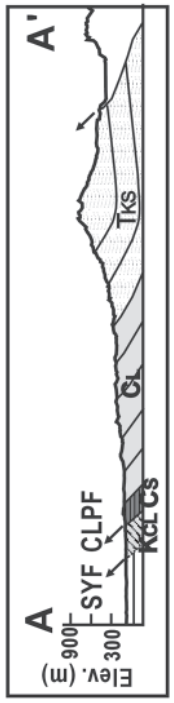

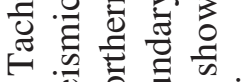

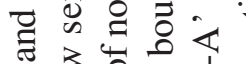

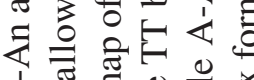

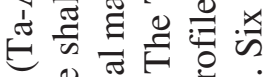

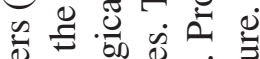

它 웡

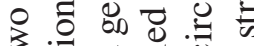

3. 멍

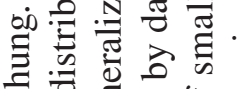

ज

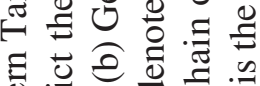

过.

苛壱合它

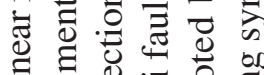

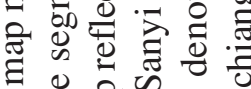

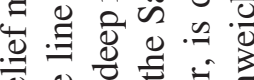

Q

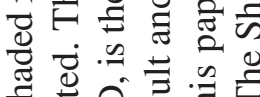

क⿺辶一兀

च

\%

ส

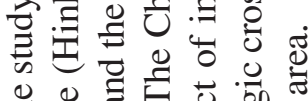

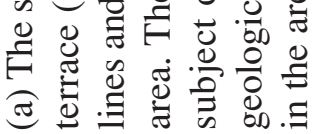$$
\therefore
$$ 
In order to investigate the peculiar northern fault, a $2 \mathrm{~km}$ well (the Taiwan Chelungpufault Drilling Project, TCDP) was proposed (Mori et al. 2002) and drilled from 2004 to 2006. In this paper, we present the seismic reflection results prepared for the site selection of this deep hole, which were rechecked after drilling. Interestingly, both deep and shallow reflection seismic methods were combined to effectively investigate the site. In this case, we attempt to use the shallow seismic method to fill in the gap when the deep seismic reflection method was unable to be utilized. These seismic profiles provide basic geologic structural information for the area, which is also needed to study the cores from the hole.

\section{REGIONAL GEOLOGY}

Figure 1 shows the geologic setting of the study area. Six major formations are involved (from old to young): the Miocene Nanchuang Formation (Nc, $400 \mathrm{~m}$ thick, protoquartzite with few coal seams); the late Miocene Kueichulin Formation (Kcl, 650 m thick, sand layers interbedded with shale); the early Pliocene Chinshui Shale (Cs, $300 \mathrm{~m}$ thick, dark gray shale and siltstone); the late Pliocene Cholan Formation $(\mathrm{Cl}, 2 \mathrm{~km}$ thick, graywacke interbedded with gray shale); the Pleistocene Toukoshan Formation (Tks, $1 \sim 2 \mathrm{~km}$ thick, gravels) and lateritic deposition (Lt) on the terraces (Fig. 1). A large monocline (the Shihweichiang syncline) forms the background structure of the top $4 \mathrm{~km}$ of the study area. The west limb of the syncline is steeper than the east (profile AA' in Fig. 1b). There are three minor folds riding on this background syncline. Of these, the Tungshih anticline represents a detached bulge formed by the detachment movement of the shallow structures above the Chinshui decollement (Lee et al. 2002; Wang et al. 2004). We will show later that the Tungshih anticline plunges to the SW, merging with the 'TT boundary' under the Tachia River (Fig. 1b). Lee et al. (2002) also gave a detailed description of the geology of this area.

The thin-skinned model is generally applied to the regional structures of western Taiwan (Suppe and Namson 1979; Suppe 1985). The Chinshui Shale is considered to be an important shallow decollement along which the Chelungpu fault slips. West of it, the Sanyi fault represents another decollement in a deeper place, that slips on the Nanchuang formation (Fig. 1b); this separates the western Taiwan foothills from the coastal plains. Thus, we have at least two 'decollement-type' faults in this area and the TCDP drill site could hit both of them. The shallow depth of both faults is probably the reason for the abnormal faulting behavior in this area.

\section{DEEP SEISMIC REFLECTION SURVEY}

The deep seismic reflection method is a useful tool for detecting regional structures. It provides a continuous profile which can reveal detailed variations in the subsurface structure down to about $6 \mathrm{~km}$. A deep seismic reflection survey, supported by our project, was shot along line D in Fig. 1, by the Chinese Petroleum Corporation (CPC) seismic team in 2002. This D profile (Fig. 2) extends $22 \mathrm{~km}$ in a NS direction, which crosses two rivers and climbs up the Hsinhse terrace. Although the topographical variation is relatively large, the quality of the profile is good. There are four purposes for this deep reflection profile: 1) tracing the 
Wang et al.

133

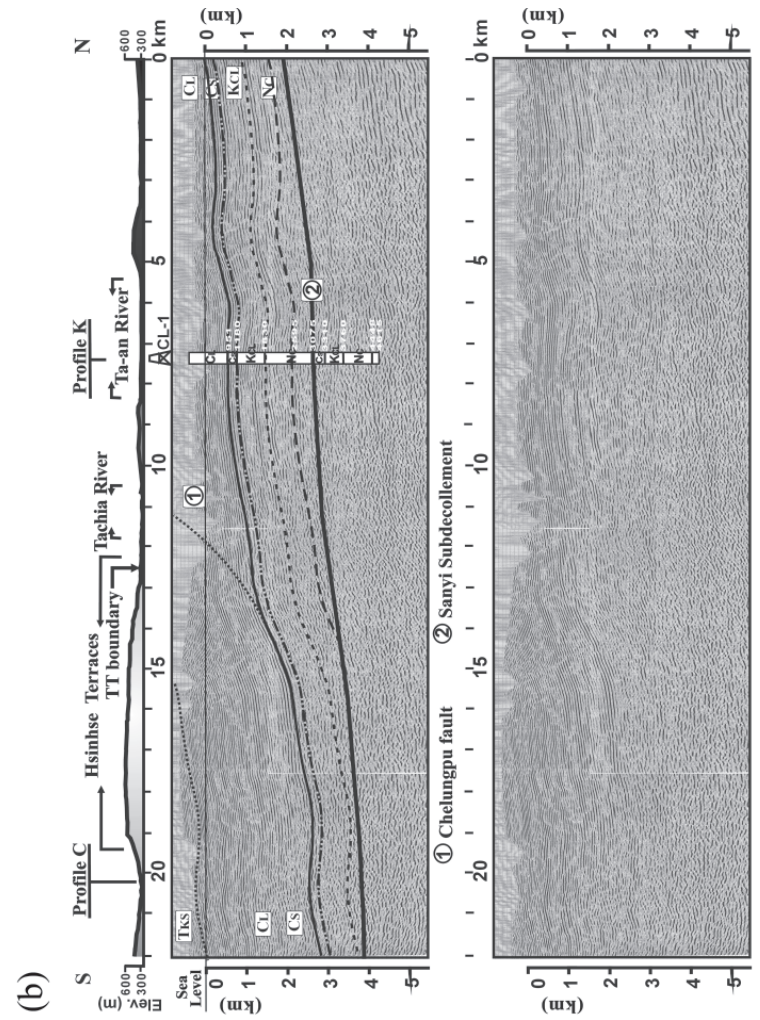

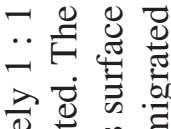

बै

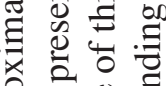

는

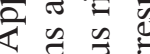

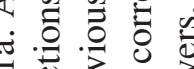

i

江. 의

$\Xi$ E

๑ $\dot{0} \dot{0}$

䟽

.0.0

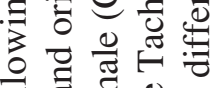

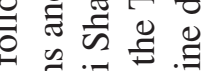

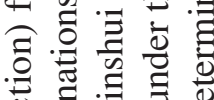

要寻要

至U
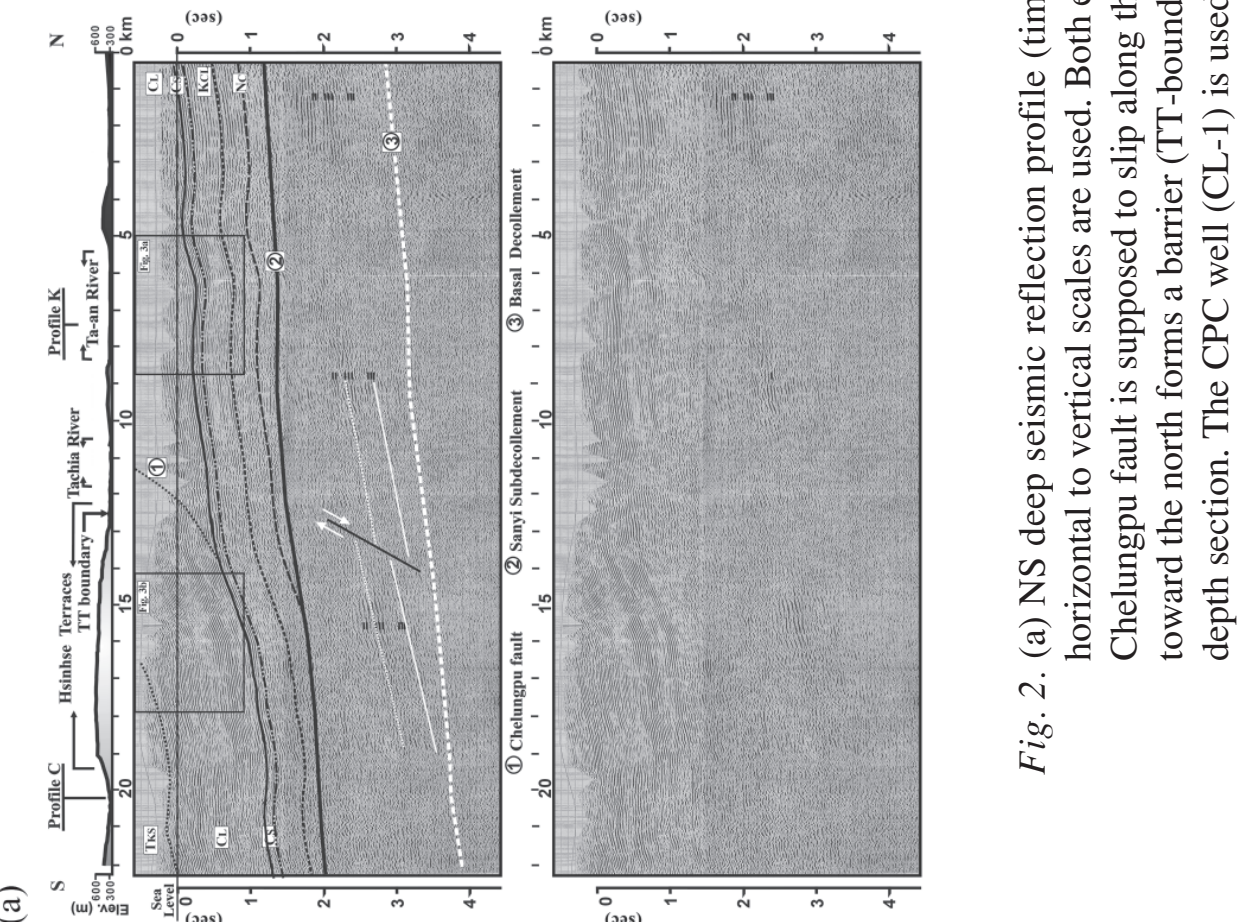
extension of the Chelungpu fault; 2) realizing the properties and the locations of the decollement; 3) mapping the inferred evolution of imbricated structures above the decollement; 4) trying to better understand the mechanism behind the earthquake faulting.

Table 1 lists the field survey parameters. They follow the standard for regular oil-exploration seismic surveys. A five-vibroseis source was operated by stacking $1015-100 \mathrm{~Hz}$ sweeps, each $20 \mathrm{sec}$ in length. The recorder used a 300 channel I/O system. The data processing followed regular CDP procedures, except that the topographic and static corrections were enhanced several times to provide an optimal result. The final time section is shown in Fig. 2a and its migrated depth section in Fig. 2 b.

A 4.5-km deep well (CL-1) was drilled by the CPC in the 1960s in this area (see Fig. 1b for the location). The well penetrated the Sanyi fault at a depth of $2.3 \mathrm{~km}$, below which the structural layers are duplicated. This well provided useful information for identifying the layers in our seismic sections (Fig. 2). First, we focus on the Chinshui Shale (Cs) which is the detachment surface for the Chelungpu fault. It is interesting to see that the Chinshui Shale ramps to the north at an angle of about 20 degrees, beneath the Hsinhse terrace and the Tachia River. The bending of the layers seems to form a flat-and-ramp geometry, which may be the cause of structural up-lifting above it. It is reasonable to assume that this uplifting may have raised the Hsinhse terraces. Thus, the sloping geometry acts like a 'lateral ramp' which could interfere with fault movement. During the 1999 earthquake, the Hsinhse terrace suffered significant ground displacement, $7 \mathrm{~m}$ horizontally and $3 \mathrm{~m}$ vertically (Yu et al. 2001). This could be attributed to detachment movement along the Chinshui Shale, i.e., the Chelungpu fault. Furthermore, the rupturing during the earthquake followed the ramp and approached the surface. The fault becomes quite shallow, thus exposing the ruptures on the surface, causing a $15 \mathrm{~km}$ long, $2 \mathrm{~km}$ wide 'en echelon' fault distributed along the Tachia River (Fig. 1b). In fact, the 3D structure revealed by the shallow seismics (Wang et al. 2004 or Fig. 5) indicates that the uplifting of the Chinshui Shale forms a boundary which follows the Tachia River and the Tongshih anticline, called the TT-boundary, trending in an EW direction (in Fig. 1b, it is indicated by the chain of small circles; also Fig. 5). The Chinshui Shale is shallower north of

Table 1. Field Survey Parameters.

\begin{tabular}{lcc}
\hline & Deep reflection & Shallow reflection \\
\hline Channel number & 300 & 96 \\
Receiver interval & $30 \mathrm{~m}$ & $2 \mathrm{~m}$ \\
Near offset & $120 \mathrm{~m}$ & $100 \mathrm{~m}$ \\
Fold & 150 & 16 \\
Record length & $5 \mathrm{sec}$ & $1 \mathrm{sec}$ \\
Frequency range & $15-100 \mathrm{~Hz}$ & $40-250 \mathrm{~Hz}$ \\
\hline
\end{tabular}


the TT-boundary, which even forms a small depression where the Ta-An River flows. From this, we can say that the Tachia and Ta-An Rivers, the two main rivers in central Taiwan, are actually of structural significance.

Figure 2 also shows that the Sanyi fault has a small dipping angle (about 5 degrees) at deeper places. This old decollement, which developed at the bottom of the Nanchuang formation $(\mathrm{Nc})$, could represent a long and large detachment boundary which allowed the movement of massive imbricated structures to over-thrust toward the surface. Many significant gas-product layers may be buried beneath this fault. Additionally, a basal decollement (probably in the Wuzushan formation, the oldest Miocence layer in Taiwan) is also indicated in Fig. 2a, although the seismic images are not clear. The shallow and low dip angle properties of these decollements mean that the structures in this area move easily and even form an important structural boundary between northern and southern Taiwan (Meng 1963).

\section{SHALLOW SEISMIC REFLECTION SURVEY}

Compared with the deep seismic reflection method, the shallow seismic reflection method is a relatively new development (Steeples and Miller 1990). It is a small scale method, modified from the oil-exploration deep reflection method. The survey size has been reduced by a factor of 10 and the expense by a factor of 100. This makes the method operable for general research institutes. The shallow reflection method focuses on near-surface shallow structure studies $(<1500 \mathrm{~m})$, and has the advantages: 1$)$ avoiding the wiggly lines in hilly areas; 2$)$ increasing efficiency of the work; and 3) obtaining high resolution near-surface profiles.

To investigate the TCDP drill site, six shallow seismic lines along profile C (Fig. 1a), have been collected. Due to the restricted size of the TCDP drilling area (only $5 \mathrm{~km}$ long), it was not possible to carry out the deep reflection survey. The shallow seismic survey used the following equipment: 1) source: EWG-III weight drop impact pulse generator; 2) receiver: OYO $40 \mathrm{~Hz}$ geophone; 3) recorder: DAS-1 96 channel seismograph. The acquisition geometry used end-on shooting and the survey parameters are also listed in Table 1 for comparing with the deep reflection. The data processing follows standard procedures for CDP data. The frequency range of obtained seismic signals is between 50 to $200 \mathrm{~Hz}$.

To show mutual properties between the shallow and deep reflection methods, we present shallow seismic sections which coincide with the deep seismic section in Fig. 3. Sections F1 and F2 are on either side of the Ta-An River, which help to constrain the structure beneath the river (i.e., a shallow depression). The reflectors in section F1 dip slightly to the south, the same as that in the background deep profile. There is abrupt layer dipping variation at $0.55 \mathrm{sec}$, which may imply a detachment movement inside the Chinshui Shale. Section F2 is not of good quality; however, its structural pattern is still in agreement with the deep reflection section. The other two sections, M1 and M2 (Fig. 3b), were taken on the Hsinhse terraces (Fig. 1a). The reflection events come from the Cholan Formation. Since sand layers are interlaced with thin mud layers in this formation, the features of reflectors are filled with strong and weak reflection signals and also expressed as high reflection continuities. This forms the signatures of 'reflection patterns', which are helpful to correlate layers on each profile. As shown in Fig. 3b, 
(a)

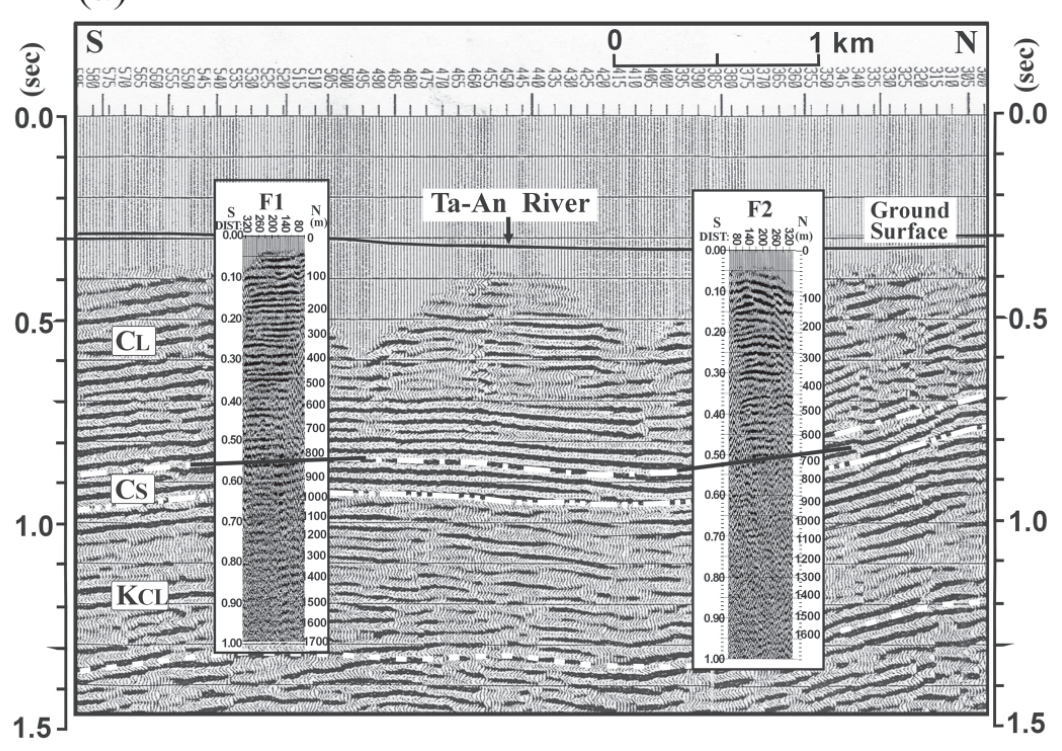

(b)

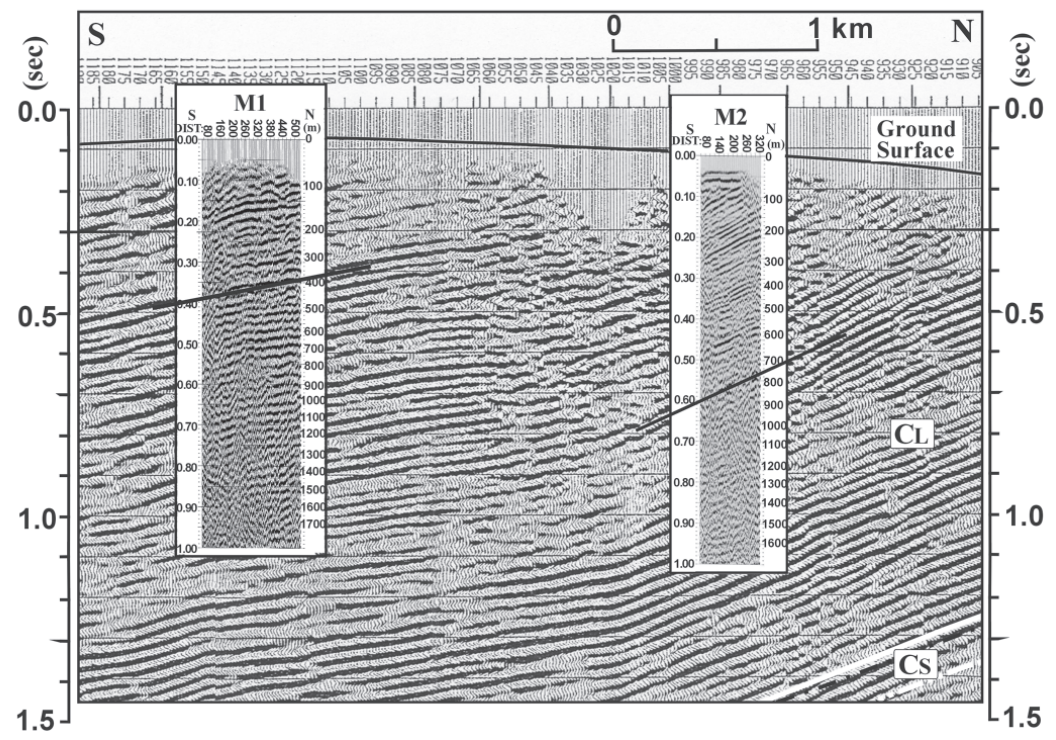

Fig. 3. High resolution shallow seismic sections are compared with the deep reflection profile D. (a) The section to the north of the TT boundary, and (b) to the south. The Chinshui Shale is shallower to the north. The layer dipping patterns are quite similar, although the shallow seismics may provide a more detailed picture of the underground structure and stratigraphic seismic tracks. 
the match of seismic reflection pattern is pretty good. The tilting of the layers in section M2 apparently comes from the bending of the whole Cholan Formation. Although the shallow reflection method only reveals a small portion of the big structures, their images are as reliable as deep reflection images.

Taking into account the merits of the shallow reflection method, we collect a series of 6 EW seismic sections that pass through the TCDP drill site, as shown in Fig. 4. The depth axes are also plotted on these time sections for scale controls. Due to the scale limitations of the method, we do not shoot a continuous profile; instead, a sequence of 6 sections is obtained, which are then put together to represent a long profile. Section $\mathrm{C} 1$ crosses the surface rupture position of the fault, which gives us a control to project the fault position down to that below the drilling site. There is another control from the line-tie with NS profile D (the deep reflection) which is at the eastern side of this profile. The layer dip angles for this area are quite uniform, about 30 degrees, which agree with the geologic dipping in surface outcrops. The Chelungpu fault is concordant within the bedding plane between the Chinshui Shale and Kerichulin Formation. All the structural and stratigraphic features are of great help in regulating the geologic situation around the well, e.g., extending it to tie in with profile D.

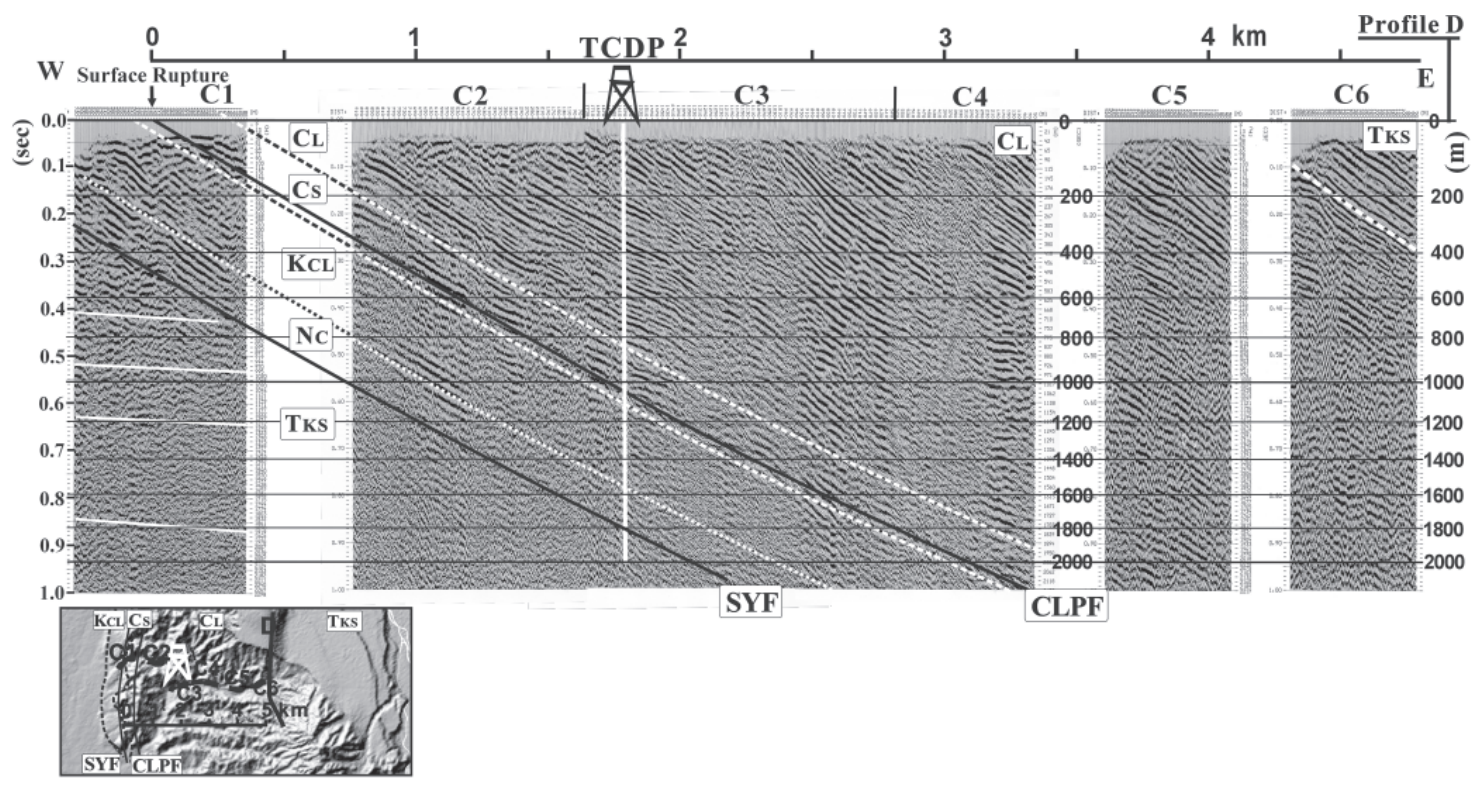

Fig. 4. A long shallow seismic section used to provide the site conditions for the TCDP well. The layers dip uniformly to the east by 30 degrees. The targeted fault slip surface (CLPF) is predicted to be met at a depth of $1100 \mathrm{~m}$ at the TCDP well and the deeper Sanyi fault (SYF) at a depth of $1800 \mathrm{~m}$. The deep reflection profile $\mathrm{D}$ offers a control on the eastern side. 
Seismic profile $C$ shows the final seismic section together with the layer interpretation (Fig. 4). It is predictable that there are two major regional faults including the Chelungpu fault and the Sanyi fault in seismic profile C. On the lower-left corner, there are nearly flat reflectors which represent the Toukoshan gravel, a Pleistocene formation beneath the older Sanyi thrust fault (SYF). The target layer at the drill site is the Chinshui Shale (Cs), which is expected to be between the depths of 900 and $1200 \mathrm{~m}$ and the fault at $1100 \mathrm{~m}$. There are the Miocene Kueichulin (Kcl) and Nanchuang (Nc) Formations between the Chelungpu and Sanyi faults. This $2 \mathrm{~km}$ well may meet the Sanyi fault at $1800 \mathrm{~m}$. On the hanging wall of the Chelungpu fault, there are some layer dipping angle variations within the Cholan Formation in sections C3 - C4 and C6. This kind of angular variation may have been a result of pressure being released near the surface, thus twisting the layers when the detachment movement occurred.

Seismic profile $\mathrm{C}$ is quite a good key line, providing information about geologic structures around the drill site. It was very useful in making a drilling plan for TCDP. Although the seismic sections may have certain imperfections, they are still of great help in describing subsurface structures. For drill sites that are difficult to access with big survey systems, shallow reflection seismics could play an important interface role between the geologic investigation and drilling projects.

\section{CONCLUSIONS}

In this paper, a deep reflection profile and a composite shallow reflection profile are combined to provide details of the geologic structure around the TCDP drill site. In addition, we have collected hundreds of shallow seismic sections in the northern fault region (Fig. 1a). From this, we have been able to build up an image of the 3D subsurface structure of the Chinshui Shale, or equivalently the Chelungpu fault, for the area. A conceptual structure pattern is shown in Fig. 5. The TT-boundary beneath the Tachia River is one of the main regional structural elements playing a role as a lateral ramp, which divides the area into two halves. North of it, the subsurface structure is quite flat and shallow $(<1 \mathrm{~km})$, forming a small depression. South of it, the structure plunges to the south fast. This structural lateral ramp could make the TT-boundary a barrier which stopped the propagation of rupturing from the south during the 1999 earthquake and caused large ground displacements. It is also interesting that the town of Shihkang (the place of the largest displacements) happens to be located at the junction between the lateral and front ramps of the Chelungpu fault. Huge ruptures were thus produced due to the merging of two components: one to the west (the Chi-Chi earthquake thrusting direction) and the other to the north (acting with the TT-boundary).

After finishing the TCDP drilling, we recognize that the 1999 Chi-Chi earthquake faulting occurred at depths of 1111 and $1153 \mathrm{~m}$, which agrees quite well with the seismic reflection prediction $(1100 \mathrm{~m})$. In addition, the deeper Sanyi fault is met at a depth of $1710 \mathrm{~m}$, also approximating the prediction value $1800 \mathrm{~m}$. The dip angles of the layers are predicted to be 30 degrees to the east and 20 degrees to the south. These dip angles are proved to be useful in controlling drill direction deviation.

The seismic sections in this paper enable us to understand the structure controlling the rupturing behavior of the Chelungpu fault at its northern end. Adequate information about the 
geological structures is also provided to aid the TCDP drilling. The following conclusions are obtained:

(1) The TT-boundary is thought to be the main structure causing huge ruptures at the northern end of the Chelungpu fault. The fault followed a lateral ramp and exposed at the surface, forming the 'en echelon' surface breakage pattern.

(2) At least two decollement boundaries are identified. The shallow Chelungpu decollement ( 1 to $1.5 \mathrm{~km}$ ) and the deeper Sanyi fault $(2.5$ to $3 \mathrm{~km}$ ). However, another possible main decollement could also exist at even deeper places. The relatively shallow depths of these decollements could be another reason for the abnormally large ruptures in this area.

(a)

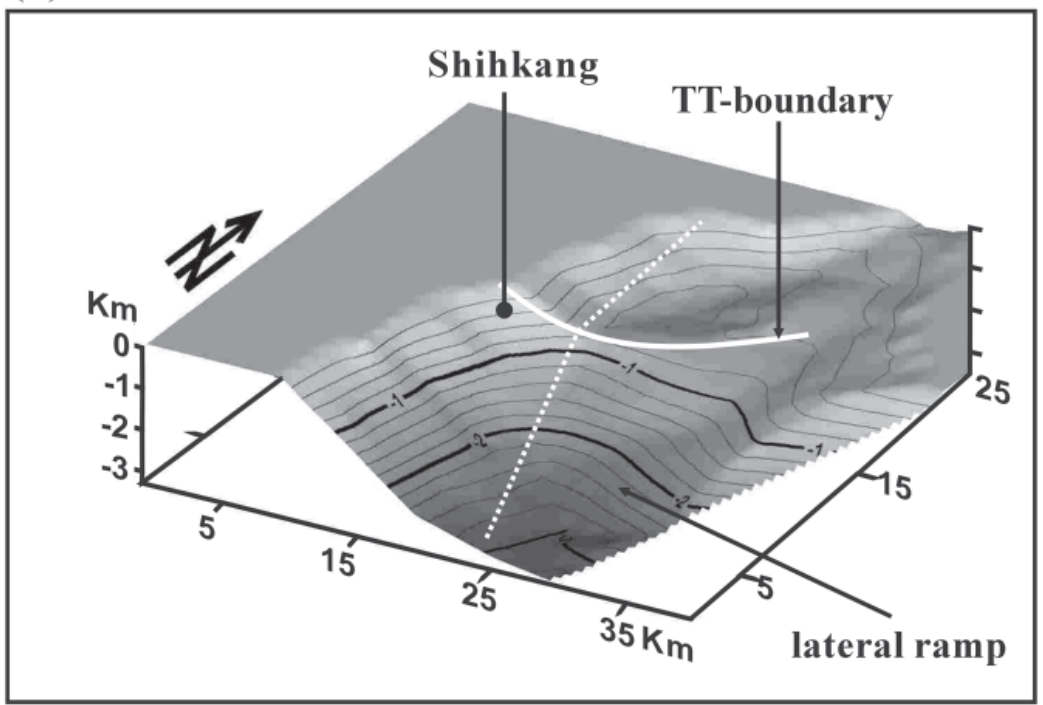

(b)

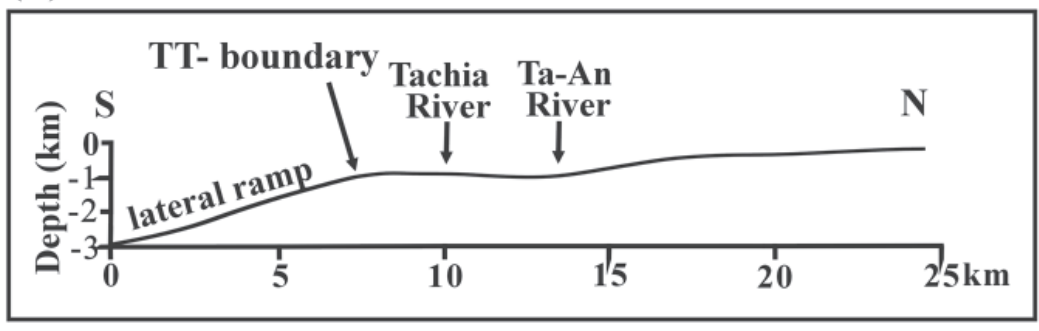

Fig. 5. (a) The conceptual 3D subsurface of the top of the Chinshui Shale. The white line represents the TT-boundary, which forms a structural boundary causing huge ruptures. The shape of a lateral ramp is obvious. The dotted line gives the position of the section shown in (b). 
(3) By combing the seismic sections from the deep reflection with the shallow reflection, we are able to predict the geologic structure around the TCDP drill site. The fault trace is confirmed to appear around $1100 \mathrm{~m}$ and the other deeper Sanyi fault at $1710 \mathrm{~m}$ after drilling.

(4) The shallow seismic reflection data is useful in investigating the regional geology, especially when used in unison with the deep seismic reflection method.

Acknowledgements This research was supported by the National Science Council of Taiwan under grant NSC 92-2116-M-008-001 and the Taiwan Earthquake Center: TEC contribution Number 00005.

\section{REFERENCES}

Hung, J. H., and K. Wiltschko, 1993: Structure and kinematics of arcuate thrust faults in the Miaoli-Cholan area of western Taiwan. Petrol. Geol. Taiwan, 28, 59-96.

Lee, J. C., H. T. Chu, J. Angelier, Y. C. Chan, J. C. Hu, C. Y. Lu, and R. J. Rau, 2002: Geometry and structure of northern surface ruptures of the $1999 \mathrm{M}_{\mathrm{w}}=7.6$ Chi-Chi Taiwan earthquake: influence from inherited fold belt structures. J. Struc. Geol., 24, 173-192.

Ma, K. F., J. Mori, S. J. Lee, and S. B. Yu, 2001: Spatial and temporal distribution of slip for the 1999 Chi-Chi, Taiwan earthquake. Bull. Seismol. Soc. Am., 91, 1069-1087.

Meng, C. Y., 1963: The San-I overthrust. Petrol. Geol. Taiwan, 2, 1-20.

Mori, J., H. Ito, and C. Y. Wang, 2002: Chelungpu fault drilling could resolve seismological issues. EOS, 83, 255 pp.

Shin, T. C., and T. L. Teng, 2001: An overview of the 1999 Chi-Chi, Taiwan, earthquake. Bull. Seismol. Soc. Am., 91, 895-913.

Steeples, D. W., and R. D. Miller, 1990: Seismic reflection methods applied to engineering, environmental, and groundwater problems. In: Ward, S. H. (Ed.), Geotech. and Environ. Geophys., Vol. I: Review and Tutorial, SEG publication, 1-30.

Suppe, J., and J. Namson, 1979: Fault-bend origin of frontal folds of the western Taiwan foldand-thrust belt. Petrol. Geol. Taiwan, 16, 1-18.

Suppe, J., 1985: Principles of Structural Geology. Prentice-Hall, Englewood Cliffs, 537 pp.

Tanaka, H., C. Y. Wang, W. M. Chen, A. Sakaguchi, K. Ujiie, H. Ito, and M. Ando, 2002: Initial science report of shallow drilling penetrating into Chelungpu fault zone. Terr. Atmos. Ocean. Sci., 13, 227-251.

Wang, C. Y., C. H. Chang, and H. Y. Yen, 2000: An interpretation of the 1999 Chi-Chi earthquake in Taiwan based on the thin-skinned thrust model. Terr. Atmos. Ocean. Sci., 11, 609-630.

Wang, C. Y., 2002: Detection of a recent earthquake fault by the shallow reflection seismic method. Geophysics, 67, 1465-1473.

Wang, C. Y., C. L. Li, and H. C. Lee, 2004: Constructing subsurface structures of the Chelungpu fault to investigate mechanisms leading to abnormally large ruptures during the 1999 Chi-Chi earthquake, Taiwan. Geophys. Res. Lett., 31, L02608, doi: 10.1029/ 2003 GL018323. 
Yu, S. B., L. C. Kuo, Y. J. Hsu, H. H. Su, C. C. Liu, C. S. Hou, C. S. Tsai, and T. C. Shin, 2001: Preseismic and coseismic displacement associated with the 1999 Chi-Chi, Taiwan earthquake. Bull. Seismol. Soc. Am., 91, 995-1012.

Wang, C. Y., C. L. Lee, M. C. Wu, and M. L. Ger, 2007: Investigating the TCDP drill site using deep and shallow reflection seismics. Terr. Atmos. Ocean. Sci., 18, 129-141, doi: 10.3319/TAO.2007.18.2.129(TCDP). 